Arteterapia. Papeles de arteterapia y educación para inclusión social ISSN: $1886-6190$

\title{
¿Cómo acompañar al principito? La interacción entre el juego espontáneo y las disciplinas artísticas en el acompañamiento arteterapéutico en la infancia
}

\author{
Raquel Vela González ${ }^{1}$
}

Recibido: 31 de marzo de 2016 / Aceptado: 14 de julio de 2016

Resumen. Este artículo pretende dar significación al juego espontáneo a partir de su interacción con las disciplinas artísticas en el contexto de la práctica arteterapéutica con niños y niñas. Las observaciones realizadas durante el acompañamiento a un niño en un dispositivo implementado en su escuela, contrastadas con las fuentes bibliográficas consultadas, permiten concretar las aportaciones del juego espontáneo en este ámbito terapéutico y su incidencia en la práctica a nivel metodológico.

Palabras clave: Arteterapia; Infancia; Juego espontáneo; Metodología; Práctica.

\section{[en] How to accompany the little prince? The interaction between} spontaneous play and artistic disciplines in the use of art therapy with children

Abstract. The main goal of this article is to give significance to spontaneous play from its interaction with the arts when using art therapy with children. Starting from the observations made during the therapeutic process of a child in an art therapy workshop conducted in his school, the article concludes with the contributions of play in that specific therapeutic area and its impact on the methodological practice.

Keywords: Art Therapy; Children; Spontaneous play; Methodology; Practice.

Sumario. 1. Juego y terapia; 2. Juego y actividad artística en el acompañamiento a "I"; 3. Conclusiones y consideraciones finales; 4 . Referencias bibliográficas.

Cómo citar: Vela González, R. (2016) ¿Cómo acompañar al principito? La interacción entre el juego espontáneo y las disciplinas artísticas en el acompañamiento arteterapéutico en la infancia, en Arteterapia. Papeles de arteterapia y educación para inclusión social 11, 325-340.

1 Universidad de Vic- Asociación para la Expresión y la Creación (AEC)

E-mail: bigtxam@gmail.com 
Ya impaciente y deseoso de comenzar a desmontar el motor, tracé rápidamente este dibujo, se lo enseñé y dije:

- Esta es la caja. El cordero que quieres está adentro.

Me sorprendí al ver iluminado el rostro de mi joven juez:

- ¡Oh, es exactamente como yo lo quería! ¿Crees que se necesite mucha hierba para este cordero?

Saint-Exupéry, en este fragmento del cuento El principito (1946, 1999), describe la entrada al juego simbólico con el ofrecimiento del dibujo de la caja. El piloto, preocupado por la reparación del avión, pinta, en un gesto poco meditado, una caja, y deja que el niño la llene con su imaginación, y acierta, claro. La caja es la metáfora donde todo cabe.

Cuando el adulto está dispuesto a reencontrarse con el niño que fue, se hace posible conectar con el imaginario del pequeño interlocutor. Como apunta SaintExúpery "todas las personas mayores han empezado siendo niños (pero hay pocas que se acuerden)".

\section{Juego y terapia}

El uso del juego con finalidades psicoterapéuticas llega con el psicoanálisis, durante el primer cuarto del s.XX. Hermine Von Hugh Hellmuth y Anna Freud fueron las primeras en aplicarlo en su práctica psicoanalítica con niños, pero es Melanie Klein quien, poco después, da un peso específico a la terapia a través del juego a partir de su utilización en el caso de un niño que se negaba a hablar en las sesiones de psicoanálisis.

Desde la psicoterapia se pueden encontrar diferentes enfoques en la aplicación de la terapia a través del juego, también llamada ludoterapia, que van desde aquellos que provienen de los planteamientos humanísticos de Carl Rogers, que derivan en la terapia Gestalt o la centrada en la persona, de la que Virginia Axline sería representante destacada, a otros orientados por las terapias psicodinámicas o el psicoanálisis. Dentro de este último grupo, destacan los trabajos desarrollados por Anna Freud, Melanie Klein, Donald Winnicott, Françoise Dolto, Arminda Aberastury o Erik Erikson.

En este contexto, se pueden hallar descritos en la bibliografía algunos casos emblemáticos que utilizan el acto de jugar y los juguetes como herramientas esenciales en la terapia. De la línea psicoanalítica destacan: el caso de Bernadette, una niña de cinco años y medio, expuesto el año 1949 por Françoise Dolto, en el que la psicoanalista trabajó con la "muñeca flor", creada por encargo de la misma terapeuta para el tratamiento; y el caso de la niña Piggle, tratada por Donald Winnicott del año 1964 al 1967 de forma esporádica en catorce sesiones y documentado en el libro Psicoanálisis de una niña pequeña (The Piggle) (The Piggle. An account of the psycho-analytic treatment of a little girl, 1977). En el ámbito de la terapia de juego centrada en el niño es remarcable el caso de Dibs, publicado el año 1964 por la psicoterapeuta Virginia Axline (2014).

Por lo que respecta a la arteterapia, el juego suele tener asignada la función de elemento facilitador de la abreacción al fomentar la desinhibición, sobretodo en adultos, pero parece que no cuenta con una caracterización propia como actividad 
creadora, sino que más bien ha sido abordado como un ejercicio preparatorio de la persona acompañada previo a la elaboración de una producción, o directamente se lo ha considerado como algo, en mayor o menor grado, intrínseco al desarrollo de las diferentes disciplinas artísticas. El arteterapeuta Rafael Ibáñez defiende, en la ponencia Arteterapia y terapia de juego. Una simbiosis destinada al éxito (2012), que "la metodología de la arteterapia infantil debería contemplar la integración de herramientas lúdicas".

El juego es inherente al desarrollo humano en sus dimensiones psíquica, social, cultural y biológica, y desde esta perspectiva se puede decir que convivimos con él de forma cotidiana. En palabras de Huizinga (2012), es una función llena de sentido, que ultrapasa aquello puramente fisiológico e instintivo y contribuye a dar sentido a la vida. Pero el juego no es la vida "corriente", como el mismo autor explica, sino que más bien consiste en "escaparse a una esfera temporera de actividad que posee su tendencia propia" (2012: 24-25). Freud (1907), desde el psicoanálisis, también describe este mundo de creación propia en relación al juego y lo equipara a la actividad artística del poeta, dejando claro lo que representa para el niño:

Sería injusto en este caso pensar que no toma en serio ese mundo: por el contrario, toma muy en serio su juego y dedica en él grandes afectos. La antítesis del juego no es la gravedad, sino la realidad. El niño distingue muy bien la realidad del mundo y su juego, a pesar de la carga de afecto con que lo satura, y gusta de apoyar los objetos y circunstancias que imagina en objetos tangibles y visibles del mundo real.

Esta esfera o mundo del que hablan los citados autores es lo que Winnicott llama tercer espacio o espacio potencial, situado entre la realidad física externa y la realidad psíquica interna del niño (2013). El espacio potencial se construye inicialmente entre el recién nacido y su madre, que debe ser suficientemente buena para permitir al mismo tiempo la separación e individuación del pequeño sin que éste pierda del todo la sensación de sostenimiento, es decir, la confianza que le permita crecer, y eso se consigue mediante la simbolización progresiva vía los objetos transicionales y el juego (Winnicott, 2013).

El juego simbólico cumple múltiples funciones desde diferentes perspectivas en el desarrollo del niño, es una manera de asimilar la cultura y conocer la realidad del mundo que le rodea, constituye un medio de expresión, experimentación y creatividad, proporciona placer y está ligado a las emociones, por lo que favorece el vínculo social, para Piaget tiene funciones compensatorias, liquidatorias y anticipatorias (citado en Abad, Ruiz de Velasco, 2012: 99), permite la liberación de agresividad y la canalización de conflictos, estimula el desarrollo de las funciones psicológicas superiores, admite la equivocación y no está vinculado a unos resultados, se practica de manera libre y voluntaria y dura mientras divierte y puede desarrollarse.

Para Winnicott el jugar tiene una importancia capital, y debe ser estudiado como tema en sí mismo, complementario del concepto de sublimación del instinto (2013: 80), la misma aptitud que se le otorga a la creación artística. 
La fundamentación teórica de la práctica arteterapéutica radica en la posibilidad que ofrece la expresión artística de trabajar los conflictos personales a partir del inconsciente y desde la metáfora, desplazando el "yo" a la producción, y de esta forma favoreciendo los procesos de transformación en paralelo respetando las defensas. Sin embargo, para que este hecho tenga efectos terapéuticos, es necesario que se dé en un marco determinado de acompañamiento.

El arteterapeuta ha de construir un espacio de contención y confianza que acoja al niño y que favorezca la interioridad, propiciando un estado de desinhibición y de libertad de creación que posibilite la evolución del niño (Klein, Bassols, Bonet et al, 2008). Esta confianza, que tiene una fundamentación básica en el saber que se le presupone al arteterapeuta - que se traduce en los aciertos en sus intervenciones y en su habilidad para construir el escenario facilitador descrito- está relacionada con la aparición del fenómeno de transferencia entre acompañante y acompañado.

Por lo que respecta al juego, Winnicott también indica que no interesa tanto intentar entender el significado del juego sino estar atento al jugar en sí (2013), se puede realizar una psicoterapia de tipo profundo sin necesidad de interpretación (2013: 96). En relación al terapeuta, apunta que, por principio, siempre ha de permitir que se establezca el goce del juego antes de utilizar su contenido para la interpretación (2006: 182).

Si se pretende avanzar en la psicoterapia, el juego ha de ser espontáneo (Winnicott, 2013: 97), ha de surgir por iniciativa del niño y el adulto no interviene condicionando la finalidad ni imponiendo una organización. Cuando se da cabida a la espontaneidad se permite la expresión libre del niño y la aparición de su imaginario.

La psicoterapia se realiza en la superposición de las dos zonas de juego, la del paciente y la del terapeuta. Si este último no sabe jugar, no está capacitado para la tarea. Si el que no sabe jugar es el paciente, hay que hacer algo para que pueda lograrlo, después de lo cual comienza la psicoterapia. El motivo de que el juego sea tan esencial consiste en que en él el paciente se muestra creador. (ibídem:100)

Este posicionamiento de Winnicott desde el psicoanálisis queda claramente ilustrado en el acompañamiento que hace a Gabrielle o Piggle, una niña que tiene dos años y medio cuando inicia la terapia y que trata hasta los cinco. En relación a este caso, el psicoanalista afirma que es imposible que un niño de esta edad pueda descifrar el significado de un juego, a menos que lo juegue y lo disfrute (2006: 182). También apunta, por lo que respecta al placer que experimenta el niño en el juego, que tal liberación de fantasía lleva a una mayor libertad en la comunicación y en la exploración de aquello malo, negro y destructivo (ibídem, 78). Se podría decir que, como pasa con el arte, hay sublimación en la experiencia placentera del juego.

La dramatización de su mundo interior permite a la niña experimentar y jugar con las fantasías que más le molestan. La posibilidad se le proporciona en pequeñas dosis, y en un marco que se ha conformado de manera suficientemente segura gracias a la habilidad del terapeuta. La 
tensión creativa en la transferencia se mantiene y el nivel de ansiedad e incertidumbre se conserva en los límites de la capacidad de la pequeña, de manera que el juego puede continuar. (ibídem, 10)

Sin abandonar el contexto del psicoanálisis, Françoise Dolto le confiere peso al objeto, al juguete, con la creación de la "muñeca flor" durante el tratamiento a Bernadette, una niña de cinco años que padecía de anorexia y tenía comportamientos muy agresivos. Esta peculiar muñeca, medio humana medio vegetal, hecha de tela de color verde, con cuerpo de persona y cabeza de margarita sin rostro, fue decisiva en la evolución favorable de la pequeña al convertirse en el "soporte de los afectos narcisistas heridos de la edad oral" (Dolto, 2000: 143) y recibiendo la proyección de toda la actitud negativa de la niña (ibídem, 135).

Los juguetes tienen el potencial de actuar como símbolos transformadores y como narradores de una historia (West, 2000: 83) desde el mundo privado de significados que cada niño posee, por esta razón, lo que funciona en terapia para un niño puede no servir para otro (Axline, 2014: 30). La simbolización asumida con estos objetos como soporte, substituye la simbolización escondida en el síntoma (Klein, Bassols, Bonet et al, 2008: 28) sin que sea necesario descubrir la metáfora.

En el acompañamiento a la infancia conviene relativizar el rol de la palabra, la introspección y la concienciación, así como contemplar la polisemia extrema de las propuestas terapéuticas. Al niño se le proponen generalmente fórmulas sucesivas diferentes y simultáneas a la vez que se ajustan y adaptan a su progresión (ibídem, 26).

Con el fin de expresarse, el niño recurre a todos los lenguajes a su alcance y a la sinestesia que se establece entre ellos. Sin embargo, para que el juego espontáneo aparezca debe existir un contexto que le sea propicio, construir el espacio potencial que lo acoja. Bruner dice que el juego no sucede al azar o por casualidad (citado en Abad, Ruiz de Velasco, 2012: 102), por lo que será necesario crear el escenario adecuado para que la magia del juego transformador se manifieste.

\section{Juego y actividad artística en el acompañamiento a "I"}

Es a raíz de la experiencia y observaciones efectuadas durante las sesiones de prácticas del Máster de Arteterapia AEC-UVic, llevadas a cabo en una escuela de educación infantil y primaria, que se concreta la decisión de investigar y realizar el Proyecto final de la formación sobre la interacción entre el juego espontáneo y la producción artística en arteterapia.

Al tratarse de un acompañamiento a niños de los que prácticamente no se disponía de información, el punto de partida fue plantear un acercamiento, tanto a nivel personal como para introducir el trabajo en el lenguaje artístico con el que se había previsto iniciar el acompañamiento, mediante juegos. Las actividades lúdicas propuestas al inicio de las sesiones pretendían: favorecer la interacción entre el cuerpo y los materiales plásticos para intentar desvincular el acto de dibujar y pintar de la parte mental y facilitar la implicación en la producción, ayudar a la progresiva familiarización con los materiales y la dinámica de las sesiones, y alejar la actividad desarrollada en el taller de arteterapia de la que se podía dar en las clases de plástica en la escuela, para diferenciarla. Sin embargo, este papel inicial 
del juego, que responde a la función que habitualmente se le atribuye, se vio desbordado al avanzar las sesiones.

El caso escogido para desarrollar el estudio fue el de "I", un niño que tenía cinco años de edad al iniciar el acompañamiento y cursaba primero de primaria. La decisión de que "I" participara en el taller fue de la Dirección del centro y contaba con la autorización de los abuelos del niño, que eran los adultos que se hacían cargo del menor, ya que "I" estaba separado de sus padres desde hacía más de un año por problemas de drogodependencia de estos. Es el mediano de tres hermanos. Tanto la hermana mayor como el hermano pequeño viven con otros familiares, cada uno en un municipio diferente, hecho que dificulta los encuentros frecuentes. A la madre la ve cada quince días y, según explicó la escuela, después de las visitas la actitud y el estado de ánimo del niño empeora. "I" entró en el colegio como alumno nuevo en el curso anterior, no tiene dificultades cognitivas pero su conducta a menudo es agresiva y pierde el control.

Las sesiones con "I" fueron individuales y de una hora y media de duración, con una frecuencia semanal a lo largo de todo el curso escolar.

El seguimiento cuidadoso y el registro sistemático del desarrollo de las veintiocho sesiones llevadas a cabo, se sintetizaron y estructuraron para el estudio mediante la definición de unos parámetros que permitieran su análisis y su contraste con aquellos datos procedentes de los casos descritos profusamente en la bibliografía consultada. Los casos publicados que se utilizaron se valen del juego como herramienta terapéutica esencial en el acompañamiento al niño desde posicionamientos compatibles con la práctica arteterapéutica de acuerdo con la línea de Jean-Pierre Klein ${ }^{2}$.

Los parámetros considerados comprenden la descripción del trabajo artístico desarrollado, del contexto arteterapéutico y de la evolución del niño, pero especialmente se concreta el detalle de los aspectos relativos al juego: si su aparición ha sido espontánea o dirigida, es decir, propuesta por la arteterapeuta, qué ha sido lo que ha desencadenado la aparición del juego espontáneo, y cuál ha sido la actitud de la arteterapeuta en relación al juego según cuatro indicadores básicos:

- observadora: no intervención.

- contención: la intervención se limita a establecer o recordar los límites de la actividad y a evitar que el niño pueda hacerse daño.

- colaboradora: se ayuda al niño, si lo solicita, a realizar alguna acción con la que tenga dificultad.

2 Jean-Pierre Klein (París, 1939) es psiquiatra, arteterapeuta, doctor en psicología, dramaturgo, autor de numerosos libros de reflexión y arteterapia, director del Institut National d'Expression, Creation, Art et Thèrapie de París y de la revista Art et Thèrapie. La línea de arteterapia que fundó hace más de cuarenta años está fuertemente vinculada a los planteamientos psicoanalíticos de Donald Winnicott, y se caracteriza por la no interpretación de la producción llevada a cabo por el sujeto, para centrarse en el acompañamiento de los aspectos formales de la obra desde una escucha sutil y profunda de la persona. Se trata de llevar la producción más allá de una expresión primera (aquella que produce casi siempre un breve alivio sintomático), para sostener su desarrollo, en el tiempo que sea necesario, hacia una obra verdaderamente creativotransformadora. 
- participante: el arteterapeuta participa del juego.

El análisis de los registros se realizó desde la mirada de la investigación cualitativa, otorgándole significación a las experiencias vividas durante el acompañamiento - en el que la arteterapeuta actúa como observadora participante dentro de la investigación - para estudiar los vínculos entre el juego espontáneo, como actividad creadora por excelencia en la infancia, y la producción artística en el contexto de un taller de arteterapia, que se construye como espacio susceptible de facilitar esta interacción y acoger las sinergias que se puedan generar.

Como resultado del análisis fue posible definir unos bloques de sesiones más o menos homogéneas en relación a la actividad desarrollada, es decir, a la producción artística, a las características de los juegos que pudieran aparecer y a la conexión entre ambos.

\section{- El entramado (B1)}

El bloque inicial, que ocuparía las siete primeras sesiones, correspondería a una fase de experimentación, en parte promovida por las propuestas que se plantean con la intención de favorecer la toma de contacto de "I" con los materiales, el dispositivo y la figura de la arteterapeuta, de manera gradual y sin prisas. Se trata de permitir que sea el niño quien tenga la iniciativa de construcción de la relación (Axline, 2014). El juego y el trabajo plástico se imbrican sin que se le pueda atribuir una identidad propia a ninguna de las dos actividades.

Este hacer un tanto enmarañado, colabora en la apropiación del tiempo y el espacio de las sesiones por parte del niño, a la vez que pone distancia respecto a las dinámicas escolares, en general de un carácter más directivo. Todos los niños necesitan su tiempo para explorar el mundo a su manera (Axline, 2014: 48). Sin embargo, algunos niños se pueden sentir desconcertados por el grado de permisividad y libertad presente en el marco terapéutico (West, 2000: 61), en especial si se desarrolla, como sucedía en el caso de "I", en el centro escolar y en horario lectivo, por eso es importante que en el acompañamiento no se intente acelerar el ritmo de los acontecimientos. El niño tiene que poder captar que en el nuevo contexto no hay una forma correcta de hacer las cosas (Axline, 2014: 51), pero sí es necesario definir en el dispositivo unos límites predictibles, consistentes y realistas para que el niño se sienta seguro (Axline, 2014: 62).

Si pudiera hacerle llegar el concepto de que no existían respuestas ocultas que él tenía que adivinar, que no existían normas ocultas de conducta o expresión más allá de las que se habían establecido abiertamente, que no tenía que leer mi mente ni encontrar ninguna solución que yo ya hubiera decidido previamente, que no había ninguna prisa por hacerlo todo hoy, entonces, quizá, Dibs podría permitirse estar más en contacto con su propio sentimiento de seguridad interno y de lo correcto acerca de sus propias reacciones, lo que lo ayudaría a poder aclararlas, comprenderlas y aceptarlas. Para llegar a conseguir eso se necesitaría tiempo, un gran esfuerzo y mucha paciencia por parte de ambos. Y debía ser llevado a cabo en todo momento, mediante un proceso básica y fundamentalmente honesto. (Axline, 2014: 51-52) 
El establecimiento de límites es una cuestión que genera dudas en el acompañamiento, tanto referidas a qué se puede y qué no en relación al espacio o el material, como a la distancia a mantener en cada situación entre el niño y el acompañante, teniendo en cuenta, además, que la incertidumbre al fijar los límites le puede restar energía a la terapia (West, 2000: 197). En el acompañamiento a "I", en más de una ocasión apareció cierto titubeo para acotar el uso del material, por ejemplo de la pintura, hasta que el derroche en el manejo se consideró como un elemento más que se integraba en las producciones del niño. Virginia Axline describe su actitud permisiva con Dibs, el niño al que acompaña, cuando éste decide derramar todo un bote de pintura al suelo y tirar contra la pared un biberón que queda hecho añicos (2014: 191-192). Seguramente este tipo de impulsos surgen de una necesidad, puede ser de contención o quizás de superación de un episodio de la historia personal del niño, por eso vale la pena valorarlos evitando caer en la interpretación o la verbalización de contenidos. Hay que estar preparado para enfrentarse a lo inesperado y, a veces, a lo no bienvenido (West, 2000: 96) y aceptarlo, porque en buena parte participa en la construcción de la transferencia.

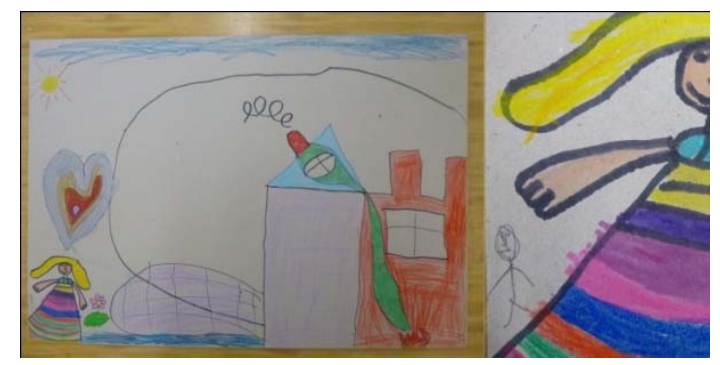

Figura 1. Primeros dibujos donde lo desagradable no tiene apariencia física (a la derecha, en lápiz detalle del secuestrador del cuento representado en el dibujo)

De las producciones creadas desde el trabajo plástico en esta etapa inicial, aparte de las de carácter más exploratorio, se pueden resaltar algunos aspectos significativos:

- $\quad$ se observó una repetición en la temática de los dibujos en la que el elemento casa y la figura femenina tienen un papel importante.

- $\quad$ se detectó una reticencia por la representación gráfica de aquello "desagradable", que tampoco se daba en la acción, aunque en la narración de cuentos sí que aparecía de forma destacable.

Estas cuestiones se consideraron indicadores de la evolución del niño que ayudarían en el seguimiento a lo largo del acompañamiento, juntamente con las apreciaciones derivadas de la observación de la globalidad del niño. Si el arte y el juego son formas naturales de expresión en la infancia, no parece necesario tener que forzar la autoevaluación de sus experiencias en la sesión según un molde rígido de respuesta estereotipada (Axline, 2014: 38) mediante la palabra.

- La complementariedad (B2)

El bloque consiguiente de sesiones tuvo como foco central de actividad un juego que surgió de forma espontánea mientras "I" realizaba un trabajo plástico de 
construcción de una casa, que había aparecido en un cuento y un dibujo anteriores: el juego de los personajes-tubo ${ }^{3}$. El papel de este juego en la terapia fue fundamental, y así lo muestra su presencia continuada a lo largo de unas doce sesiones - lo que supone la mitad del tiempo del acompañamiento- y su mantenimiento en el trasfondo del resto de sesiones hasta el final.

Se pueden diferenciar dos etapas dentro de este período:

- $\quad 1^{\mathrm{a}}$ etapa, de la sesión 8 a la 14 (B2.1)

"I" crea los elementos del juego a partir del material que hay en el taller, sobre todo tubos y cajas de cartón, y también utiliza el mobiliario del aula como escenario de la acción. Los personajes que participan así como la escena tienen un tono neutro, muy poco caracterizado. "I" simplemente singulariza cada personajetubo anotando su nombre en lápiz sobre la superficie de cartón. La factura del resto de componentes es de la misma sencillez. De esta manera, los juguetes construidos cumplen su función simbólica y al mismo tiempo facilitan su manipulación de forma enérgica, necesaria por el carácter violento del juego, sin tener que preocuparse de su conservación. A menudo "I" acababa estropeando o rompiendo elementos y él mismo los substituía por otros. Winnicott (2006: 181) apunta que un mismo objeto puede utilizarse con diferentes funciones durante el juego.

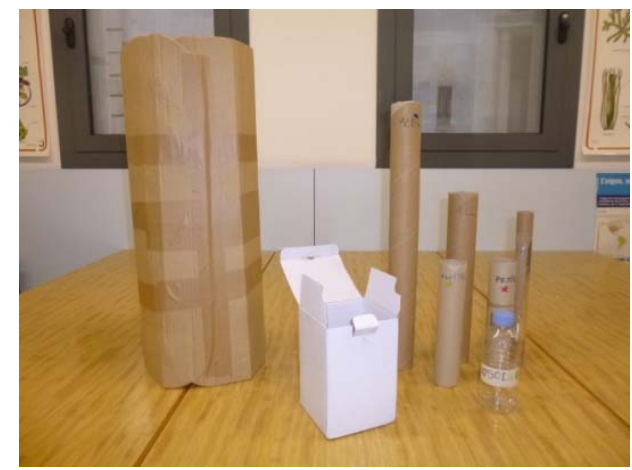

Figura 2. Elementos del juego de los personajes-tubo

Existen diversos posicionamientos sobre el destino del material de "deshecho", hay terapeutas que opinan que debe ser el niño el que decida si quiere deshacerse $o$ no (West, 2000: 147), mientras que, por ejemplo, la psicoanalista Françoise Dolto, defendía que ni tan siquiera convenía conservar los objetos fabricados por los niños

\footnotetext{
Juego de los personajes-tubo: A partir de una conversación imprevista entre la arteterapeuta e "I" a través de unos tubos de cartón, se inicia un juego simbólico con el mismo material que se propone para la construcción de una casa como continuación de un dibujo. En el juego interactúan diferentes objetos investidos por el niño (tubos y cajas de cartón, mobiliario del aula,...) para dar lugar a todo un mundo de creación propia. Los diferentes personajes-tubo se identifican por el nombre, que "I" escribe en lápiz sobre el cartón, en un principio se niega a dibujarlos más, aunque más adelante añade algún detalle gráfico a cada uno. El juego se caracteriza por un nivel de violencia extremo entre los personajes. Surgen agresiones, maltratos, humillaciones, sadismo, luchas... que se van modulando e integrando en la trama del juego. Prácticamente todos los personajes y también sus casas son destruidos y creados nuevamente en diversas ocasiones. No se reconoce una narrativa clara, cada sesión supone una sorpresa que va aportando nuevos ingredientes a este universo único, pero los roles de los diferentes protagonistas y su evolución a medida que avanza el juego sí son identificables dentro de la propia ficción.
} 
"estamos a hoy, lo que hiciste la última vez no es lo que has de hacer hoy " (2006: 141), y así se lo exponía al niño en la sesión.

Durante este período del acompañamiento, "I" aún sale a veces de la simbolización. En un momento determinado del juego puede ser que un trozo de papel de seda azul deje de ser agua y se convierta de nuevo en papel, o que un personaje vuelva a ser una botella de plástico perdiendo así su identidad fantástica, como si la magia desapareciera.

En el contexto de violencia y agresividad aceptada del juego, en alguna ocasión los combates entre los personajes de cartón creados por "I" se trasladan a una lucha real entre acompañante y niño, que se modula con la premisa que se desarrolle "a cámara lenta". Este acercamiento físico y la participación de la terapeuta en la representación, comportan un cambio en la percepción del otro y tiene repercusiones en la construcción del vínculo y la transferencia.

Otra ocasión de interacción se da cuando se practica algún trabajo plástico en el que es necesaria la intervención del adulto, bien sea para prevenir accidentes o colaborando en alguna tarea si el niño lo solicita, pero tanto en este sentido como en otros aspectos del acompañamiento, no se debe contribuir a crear una relación que genere dependencia, conviene que el niño se enfrente a los factores de realidad (Axline, 2014: 39, 53) sin caer tampoco en el abandono.

- $\quad 2^{\text {a }}$ etapa, de la sesión 15 a la 19 (B2.2)

La actividad plástica gana presencia aunque la acción entre los diferentes elementos del juego continúa siendo la protagonista principal. "I" añade detalles tanto a los personajes como a las cajas y construcciones que constituyen sus casas. El juego ha madurado, los roles de los personajes están más establecidos, pero existe cierto estancamiento en la acción, que "I" resuelve en cierta manera incorporando personajes que provienen del exterior, son muñecos de peluche, pequeños animales que trae de casa o que le presta algún compañero. Todos tienen su historia y son susceptibles de generar nuevas tensiones en la trama de la actividad lúdica.

Ahora "I" ya no sale de la simbolización durante el juego y es capaz de investir cualquier objeto con la carga simbólica que le da acceso a la ficción. Por otro lado, en las representaciones gráficas que realiza en paralelo vinculadas al juego, continua plasmando únicamente cosas bonitas, lo desagradable no tiene apariencia física a pesar del alto contenido de agresividad del juego y la violencia que también expresa "I" en los cuentos que narra.

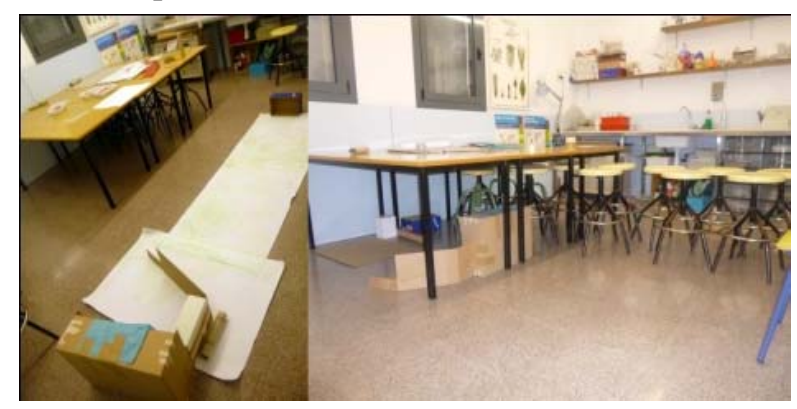

Figura 3. Escenas del juego de los personajes-tubo 
Otro factor a considerar en esta etapa que supuso un progreso en el establecimiento del vínculo, fue cargar al niño a caballo desde la sala donde se realizaba el taller de arteterapia hasta su clase al fin de la sesión. Esta situación coincidía con la salida de sus compañeros de curso, de manera que se cruzaban en el pasillo, objetivo final de "I". Así, un hecho que el primer día fue anecdótico y sin voluntad de continuidad, acabó convirtiéndose en el ritual compartido de cierre de las sesiones hasta su final.

\section{- $\quad$ El intercambio (B3)}

El siguiente bloque corresponde a las sesiones 20 a 24, y tiene un carácter heterogéneo dentro de formar un conjunto que tiene como rasgo común ser pequeños diálogos o conversaciones entra la actividad plástica y la lúdica, que a su vez se enlazan con todo lo acontecido en los encuentros anteriores. Durante estas sesiones, puede ser que aquello que empieza como un juego acabe transformándose en una producción plástica o que el trabajo en un dibujo lleve a la necesidad de una forma de expresión diferente que dé respuesta a las tensiones que se puedan haber generado, sin que necesariamente se dé continuidad de una sesión a la siguiente. En el trasfondo, los personajes-tubo continúan haciendo acto de presencia como recurso conocido donde las pulsiones tienen nombres propios escritos sobre cartón. Cabe observar que, cuando la iniciativa se deja al individuo, éste selecciona el terreno en el que se siente más seguro (Axline, 2014: 50), pero es desde esta zona segura, en la que las defensas se mantienen a salvo, desde donde se puede iniciar el viaje hacia lo simbólico.

En relación al acompañante, "I" busca el contacto físico con provocaciones planteadas dentro del juego. Estos actos agresivos, dentro del ámbito del "como si", están destinados a liberar los impulsos del niño transmitiéndoselos al terapeuta (Winnicott, 2006: 105). Los ataques hacia el acompañante acostumbran a no ser personales, sino que se dirigen contra lo que representa en la psique del niño (West, 2000: 88). Este tipo de acercamiento es diferente al que se establece en el juego de la lucha "a cámara lenta" porque se sitúa fuera del contexto del juego de los personajes-tubo y, por tanto, el rol del terapeuta es otro.

El acompañante que participa de la invención del niño puede llegar a desarrollar diferentes roles a lo largo de una sesión o del tratamiento, dependiendo de qué papel juegue en relación al niño y a la transferencia (Winnicott, 2006: 181). Se podría decir que el terapeuta es "utilizado" por el niño y debe saber dejarse llevar por el juego, disfrutarlo incluso desde la incertidumbre, porque a veces, la lectura del tema del juego solo es posible en retrospectiva (West, 2000: 113).

En todas las ocasiones el analista tuvo la impresión de ser informado por la niña de un problema específico, si bien hubo muchas áreas de juego indeterminado o conducta, o conversación en las cuales parecía faltar orientación. Esas fases de juego indeterminado constituían a todas luces un rasgo importante para extraer del caos un sentido, el de la dirección del desarrollo, y la niña alcanzaba, a través de ellas, a experimentar una sensación de auténtica necesidad, la necesidad que la había impelido a pedir otra sesión. (Winnicott, 2006: 23-24) 
Aunque todo lo que ocurre en una sesión cumple su papel en el eventual proceso de transformación del niño, de este conjunto de encuentros tienen especial significación dos, que comportan saltos en la evolución del niño, observables a partir de los cambios respecto a los patrones que sirven de indicadores en el seguimiento, que ya se han descrito anteriormente.

En todo este bloque, la actividad plástica y el juego se alimentan mutuamente en una especie de intercambio de atributos. Antes se ha visto que en el período inicial también se daba un entrelazamiento de las dos actividades, pero en aquel caso, su valor principal consistía en construir el marco propicio para la creación desinhibida e implicada. Ahora, una propuesta en un lenguaje representa un estímulo para generar una respuesta en otro código que incide en la construcción de una nueva vía, de un camino alentador, a pesar de la incertidumbre que le rodea.

En una de las sesiones (21) un juego ${ }^{4}$ que se inicia con la acción espontánea de lanzar objetos contra una pared, acaba convirtiéndose en un dibujo donde por primera vez aquello intolerable toma forma. Una acción que surge como una necesidad de descarga de tensión, pasa por un estadio de interpelación verbal directa a alguien que la pared representa con la pregunta insistente " Dime tu nombre! ¡Dime tu nombre!", y la respuesta es recogida en el papel en forma de personaje al que "I" le atribuye todos los rasgos menospreciables desde su subjetividad.

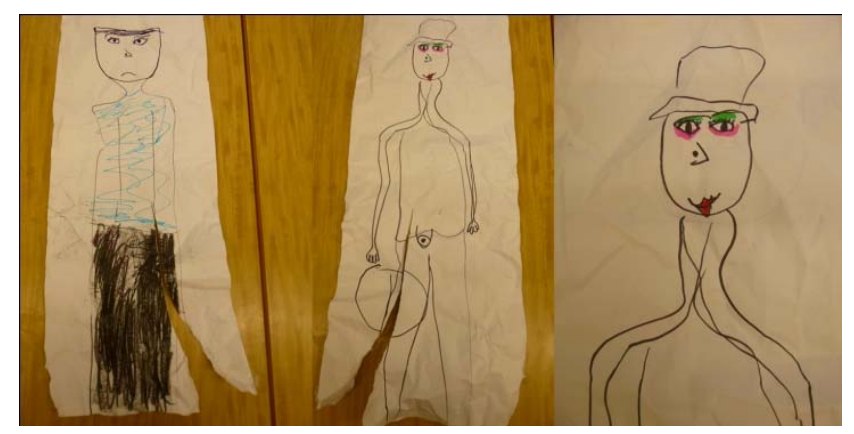

Figura 4. Representación del hombre sin nombre (sesión 21). Anverso, reverso y detalle.

En otra sesión (23), se dan dos circunstancias que también apuntan hacia una evolución en el proceso de transformación de "I". Por un lado, el estilo del dibujo de la escena habitual de "casa en un entorno amable" es diferente. El grado de estereotipo es mucho menor, y la constante figura de la niña o chica, es substituida por la de un chico. La peculiar vivienda que dibuja está formada por dos casas, una sobre la otra, y el chico vive en la de arriba, según explica "I". En el centro de la escena revolotea una mariposa. Cuando da por acabado el dibujo quiere jugar, y después de librar una breve lucha "a cámara lenta" utilizando un rollo de cartón, se sube a la mesa para seguir jugando, quiere estar arriba. A continuación empieza

$4 \quad$ Juego de lanzar bolas de papel: se trata de una actividad propuesta para facilitar la descarga física y reducir la tensión corporal de "I" que consiste en lanzar una bola de papel contra una pared, este gesto se acompaña de sonidos, palabras,... aquello que surja en el momento. 
otro juego 5 en el que "I" utiliza el rollo de cartón para fastidiar y humillar el personaje que encarna la arteterapeuta. En esta ocasión, a diferencia de otras veces, el niño acepta divertido y por primera vez, representar durante un rato el papel de víctima de los ataques y las vejaciones.

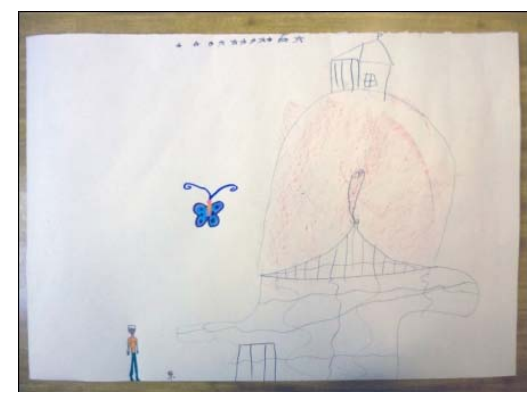

Figura 5. Dibujo sesión 23

En ambos casos hay una secuencia, que puede ser más directa o más segmentada, de procesos de creación que alternan el juego y la plástica en una narración que, según Piaget, vincula los dominios interno y externo del niño (citado en West, 2000:96).

\section{- El principito crece (S25)}

La sesión 25 no forma parte de ningún bloque porque, y aún no siendo la última, se constituye de forma espontánea, en una especie de revisión o recapitulación final promovida por "I", de todo lo acontecido en el taller de arteterapia, quizás porque en alguna sesión previa se le había anunciado la proximidad del término del taller.

En este encuentro el niño decide rehacer el dibujo que había creado en la primera sesión como portada de la carpeta donde guarda las producciones, diciendo "ahora dibujo mejor". Mientras dibuja, pidiéndome que participe, explica de forma concisa y franca su evolución personal desde el inicio de nuestros encuentros hasta ese momento. Esta exposición es bienvenida y aceptada porque surge por iniciativa de "I". Al rato, quiere trepar a un taburete colocado sobre la mesa, y desde allí arriba tiene la posibilidad de revisar todas las producciones que ha ido elaborando a lo largo del acompañamiento, y que el último día quiso llevarse a casa en su totalidad.

En sesiones anteriores también aparece la acción de rehacer un dibujo previo porque ya no satisface a "I" o ya no se siente identificado. También se repite la necesidad de encaramarse, de sentirse en lo alto o grande, quizás relacionado con la maduración natural del niño o con un sentido de empoderamiento. En el trabajo con niños, hay momentos donde es difícil distinguir los progresos debidos a la maduración emocional de los que puedan provenir de la terapia (Winnicott, 2006:

Juego del rollo de cartón: el juego consiste en el lanzamiento imaginario, a través de un rollo o tubo largo de cartón, de todo tipo de elementos o substancias desagradables (fuego, agua a presión, viento, orines, vómito...) dirigidos al personaje que encarna la arteterapeuta y de los que tiene que librarse. En la dinámica aparecen agresiones, pero en este juego el tono es más lúdico, no se percibe prácticamente tensión y se dejan oír las risas. 
22). Seguramente en este caso, como pasa en la interacción entre el juego y la producción artística, la suma favorece la alquimia que deriva en la mejora en el bienestar del niño.

\section{Conclusiones y consideraciones finales}

A lo largo de la exposición se ha reiterado la importancia capital que tiene el juego en el desarrollo del niño y en concreto en lo que respecta a su expresión creativa. El juego es natural en la infancia y emerge de forma espontánea si tiene ocasión de hacerlo.

Se quiere subrayar que en ningún momento se ha pretendido menospreciar el uso que actualmente se hace del juego como herramienta empleada en terapia con niños, pero sí se ha creído oportuno incorporar argumentos para valorizar su aplicación en el ámbito de la arteterapia en la infancia.

En este sentido, el resultado del análisis de las observaciones realizadas durante el taller, contrastadas con los casos descritos en la bibliografía consultada, permite inferir una serie de consideraciones vinculadas al contexto concreto del caso estudiado, en la línea de aportar mayor significación al papel del juego como elemento esencial del espectro creador del niño y en relación a las disciplinas artísticas. Como valores y rasgos específicos con los que contribuye el juego espontáneo se destacan los siguientes:

- $\quad$ el juego es la manera natural de los niños de expresar su potencial creativo y poner en relación los dominios interno y externo.

- facilita la implicación del niño al ofrecerle la posibilidad de expresarse en un código que le es propio y consubstancial.

- $\quad$ favorece el acompañamiento a niños de muy corta edad.

- $\quad$ promueve el acercamiento a determinadas disciplinas artísticas cuando su producción va ligada al juego, al hacerlas más atractivas. - $\quad$ incrementa la multidisciplinariedad y la imbricación de los diferentes lenguajes expresivos.

Anteriormente ya se ha indicado que la aparición de procesos creadores se ve favorecida por las características del marco arteterapéutico, y en consecuencia, en el caso de acompañamiento a niños, también facilita el surgimiento del juego espontáneo como forma de expresión básica del impulso creador en la etapa infantil. La oportunidad de poner en contacto estas dos actividades de creación, arte y juego espontáneo, en el contexto de la arteterapia, posibilita una relación simbiótica entre ellas que beneficia los procesos de transformación en el niño.

El tipo de vinculación que se establece entre la actividad lúdica del niño y sus producciones plásticas y narrativas puede oscilar en nivel de intensidad y tener un carácter diverso según el momento del proceso, como se ha puesto de manifiesto en la descripción del caso "I":

Relación de imbricación o entramado: no se le atribuye una identidad propia diferenciada al juego respecto a la producción artística.

- $\quad$ Relación de interdependencia o complementariedad: funciones complementarias de la actividad lúdica y artística en la producción. 
- $\quad$ Relación de diálogo o intercambio: estimulación recíproca entre el juego y la producción artística.

En el caso estudiado, ha tenido un peso importante en la evolución favorable del niño el juego de los personajes-tubo, en el que la mayor parte de los elementos que interactuaban habían sido construcciones o manipulaciones hechas por el propio niño a partir de material presente en el taller, o aportado con posterioridad según las necesidades. Estas elaboraciones creadas en el sí del juego espontáneo susceptibles de destruirse, rehacerse o modificarse por el mismo niño, que es quien las ha concebido - se constituyen como objetos únicos donde el niño proyecta contenidos internos. Esta doble carga subjetiva que comporta el trabajo desde el juego y las artes, facilita la implicación y el acercamiento al imaginario personal del niño.

Sin embargo, en el desarrollo del juego espontáneo, el niño no solo proyecta contenidos sobre los objetos creados, sino también en la figura del arteterapeuta cuando le hace participar del juego, asignándole diferentes roles según el papel que juegue, nunca mejor dicho, en la transferencia. Este hecho constituye una prueba de la formación del espacio potencial entre ambos y, por tanto, puede entenderse como un indicador del establecimiento del fenómeno de transferencia.

El posicionamiento que adopta el arteterapeuta puede favorecer la interacción del juego con actitudes como:

- $\quad$ situar la mirada no solo en dar continuidad a las producciones nacidas de las disciplinas artísticas, sino también a aquellas acciones que podrían considerarse como periféricas o sin significación que acontezcan en la sesión de forma espontánea como pequeños juegos, ya que pueden ser la semilla o el inicio de un proceso creativo implicado.

- $\quad$ estar dispuesto a participar del disfrute sincero del juego del niño y a desarrollar los diferentes roles que se le asignen dependiendo de su papel, en relación al acompañamiento y la transferencia.

- $\quad$ ajustar la escucha atenta para posibilitar la vinculación de la actividad lúdica y artística y aprovechar las aportaciones de cada una de ellas en favor del proceso terapéutico.

También hay cuestiones en el diseño del dispositivo que cabría tener en cuenta:

- debería garantizar la posibilidad de la expresión libre del niño en el juego en lo que respecta al espacio y a los materiales, en el sentido de disponibilidad y también de seguridad, para favorecer la autonomía del niño. Es decir, se tiene que conformar un entorno adecuado para el desarrollo del juego.

- $\quad$ tendría que contar con abundante material, variado y versátil, a la vista y de fácil acceso, aparte del que se utilice para la actividad artística, que permita al niño su manipulación para construir elementos para el juego.

Llegados a este punto se puede afirmar que a lo largo de la exposición se han proporcionado argumentos para significar y reforzar la función del juego espontáneo en el contexto de la arteterapia, y se han ofrecido algunas herramientas 
que pueden servir en su práctica a arteterapeutas y mediadores que acompañen a niños.

No obstante, también se abren nuevos interrogantes sobre el tema de estudio ¿Cómo afecta la edad del niño en las posibilidades terapéuticas de la interacción entre las artes y el juego? ¿Sería apropiado extender el uso del juego como elemento significativo en el acompañamiento arteterapéutico a adultos? ¿Las dificultades en la simbolización por parte del niño, pueden imposibilitar la aparición del juego? O por el contrario, ¿el estímulo en el uso del juego mejoraría la capacidad de simbolización de un niño con este tipo de problemas? ¿Se proporcionan suficientes espacios y tiempo a los niños para que puedan desarrollar el juego espontáneo en la medida de sus necesidades? ¿Qué respuesta da la escuela y el actual modelo educativo y de práctica pedagógica a las necesidades vitales de expresión creadora, en el juego y también en las artes, a los niños? Y en este sentido, ¿sería favorable la incorporación de dispositivos arteterapéuticos en el sí de la escuela?

Al arte y al juego espontáneo de los niños a menudo se les acusa de lo mismo, su inutilidad, aunque está más que probada la importancia de uno y otro como actividades de la expresión creadora del ser humano que colaboran, entre otras cosas, en la conformación de la identidad del individuo. Sería deseable que los principitos y princesitas de carne y hueso no fueran víctimas de esta visión obtusa de la actividad lúdica y artística, a diferencia de lo que vivió el personaje del piloto de Saint-Exupéry (1999), que explica en el cuento como "las personas mayores" lo apartaron a los seis años de su afición por el dibujo por considerarla una pérdida de tiempo.

\section{Referencias bibliográficas}

Abad Molina, J.; Ruiz de Velasco Gálvez, A. (2012) El juego simbólico. Colección Biblioteca de infantil núm. 31. Barcelona. Ed. Graó.

Axline, V. (2014) Dibs en busca del si mismo. Desarrollo de la personalidad en la terapia del juego. Valencia. Ed. PUV Universidad de Valencia. (Ed. Orig. 1964)

Dolto, F. (2006) En el juego del deseo. Madrid. Ed. Siglo XXI

Freud, S. (1907 [1908]) “El poeta y los sueños diurnos". [en línia]

http://www.biblioteca.org.ar/libros/211753.pdf

Huizinga, J. (2012) Homo ludens. Madrid. Alianza Editorial (Ed. Orig. 1954)

Ibáñez, R. (2013) “Arteterapia y teràpia de juego" [en linea]

http://prezi.com/kowyc4emfeqj/arteterapia-y-terapia-de-juego/

Klein, J.P.; Bassols, M.; Bonet, E. (Coords.), Ávarez, J.; Davidson, M.; Gómez-Franco, A.; Monsegur, T.; Moret, Z.; Pagán, J.M. (2008) Arteterapia. La creación como proceso de transformación, Barcelona. Ed. Octaedro.

Saint-Exupéry, A. (2001) El Principito. Barcelona. Ed. Salamandra. (Ed. Orig. 1946)

West, J. (2000) Terapia de juego centrada en el niño. México D.F. Ed. El Manual Moderno

Winnicott, D.W. (2006) Psicoanálisis de una niña pequeña (The Piggle). Barcelona Ed.

Gedisa. (Ed. Orig. 1977)

Winnicott, D.W. (2013) Realidad y Juego. Barcelona. Ed. Gedisa. (Ed. Orig. 1971) 